\title{
A business analytics capability framework
}

\section{Ranko Cosic}

University of Melbourne

rankocosic@hotmail.com

\author{
Graeme Shanks \\ University of Melbourne \\ gshanks@unimelb.edu.au
}

\section{Sean Maynard}

University of Melbourne

seanbm@unimelb.edu.au

\section{Abstract}

Business analytics (BA) capabilities can potentially provide value and lead to better organisational performance. This paper develops a holistic, theoretically-grounded and practically relevant business analytics capability framework (BACF) that specifies, defines and ranks the capabilities that constitute an organisational BA initiative. The BACF was developed in two phases. First, an a priori conceptual framework was developed based on the ResourceBased View theory of the firm and a thematic content analysis of the BA literature. Second, the conceptual framework was further developed and refined using a three round Delphi study involving 16 BA experts. Changes from the Delphi study resulted in a refined and confirmed framework including detailed capability definitions, together with a ranking of the capabilities based on importance. The BACF will help academic researchers and industry practitioners to better understand the capabilities that constitute an organisational BA initiative and their relative importance. In future work, the capabilities in the BACF will be operationalised to measure their as-is status, thus enabling organisations to identify key areas of strength and weakness and prioritise future capability improvement efforts.

Keywords: Business Analytics; Resource-Based View; Thematic Content Analysis; Business Analytics Capability Framework; Delphi Study.

\section{INTRODUCTION}

Business analytics (BA) systems provide benefits to organisations by enabling improvements to business processes, firm performance and creating competitive advantage (Davenport and Harris, 2007). BA systems include the people, processes and technologies involved in the gathering, analysis and transformation of data used to support organisational decision-making (Negash 2004). BA technologies include: data warehousing, reporting, visualisation, online analytical processing (OLAP), forecasting, predictive modelling and statistical analysis (Watson 2010). Although empirical evidence shows that BA systems bring benefits to organisations (Kohavi et al. 2002; Allmendinger and Lombreglia 2005; Piccoli and Watson 2008), few studies provide a sound theoretical basis for understanding how and why these benefits are achieved. The resource-based view theory of the firm provides this theoretical base. Hence, in this study, we draw upon the resource-based view theory to identify and define a set of capabilities that constitute an organisational BA initiative.

This research is important for three reasons. First, BA continues to be the top investment priority of chief information officers (Gartner 2015). Second, many organisations are making large strategic investments in BA. This trend forecast to continue with global spending expected to reach $\$ 143.3$ billion dollars by 2016 (ComputerWeekly.com 2013). Third, there is a strong need for a holistic, theoretically grounded and practically relevant BA capability framework (BACF) that can help explain how organisations achieve benefits with BA systems.

The BACF is developed in two phases. First, an a priori conceptual framework is developed based on the resource-based view and a thematic content analysis of the BA literature. Second, 
a Delphi study is used to refine and validate the framework structure, components and detailed capability definitions. Furthermore, the Delphi study is used to rank the BA capabilities based on importance. Participants in the Delphi study include both academic and practitioner experts, resulting in a BACF that is both theoretically grounded and practically relevant.

The paper is organised as follows. First, we discuss relevant background literature. Next, we describe and justify the thematic content analysis and delphi study research approaches used to develop and refine the BACF. Following that, we present the revised BACF and explain the revisions and clarifications that resulted from each round of the Delphi study. Finally, we conclude the paper with some implications of the work for academic researchers and industry practitioners, and suggestions for future research.

\section{BACKGROUND}

In this section, three areas of relevant literature are reviewed. These include: (i) the resourcebased view and dynamic capabilities; (ii) use of the resource-based view in Information Systems (IS) research; and (iii) BA capabilities and frameworks.

\subsection{Resource Based View and Dynamic Capabilities}

The resource-based view is the dominant theory in the field of strategic management research (Barney 1991). It conceptualises organisations as bundles of capabilities and resources. In the resource-based view a capability is the ability to utilise resources in order to perform a certain task (Wernerfelt 1984). These resources may be tangible (e.g. technology and people) or intangible (e.g. data, processes, skills and knowledge) (Barney 2001). To be a source of Sustainable Competitive Advantage (SCA), capabilities and resources must be valuable, rare, inimitable and non-substitutable (VRIN).

- Valuable - enable an organisation to implement a value-creating strategy;

- $\quad$ Rare - in scarce supply;

- Inimitable - cannot be copied by rivals;

- $\quad$ Non-substitutable - cannot be countered by a rival with a substitute.

A limitation of the resource-based view is that it is relatively static, and does not take into account the rapidly changing nature of dynamic business environments (Teece and Pisano 1994). Dynamic capabilities were conceptualised in order to overcome this limitation (Barreto 2010). Dynamic capabilities enable organisations to continuously renew and reconfigure their resource base in order to keep pace with rapid changes in the business environment. Dynamic capabilities comprise three organisational routines: sensing, seizing and reconfiguration (Teece et al. 1997). Sensing and seizing involve identifying and prioritising BA-enabled business opportunities. Reconfiguration involves implementing selected BA-enabled business opportunities by creating new resource configurations (Helfat et al. 2007; Sharma and Shanks 2011).

\subsection{The Resource Based View in Information Systems Research}

In IS research, the resource-based view has been used to explain how IS capabilities and Information Technology (IT) resources lead to benefits including organisational value (Raber et al. 2012) and SCA (Barney 2001). The resource-based view in IS literature delineates the distinction between IT resources and other organisational resources. For example, IT resources include computer networks, hardware, software and data whilst other organisational resources encompass people, processes and routines (Wade and Hulland 2004; Arial and Wiell 2007; Nevo and Wade 2010). Three key findings that emerge from this literature stream are as follows.

First, it is highly unusual to find a VRIN IT resource per se (Wade and Hulland 2004). This is because IT resources have become increasingly commoditised (Gartner 2009) and can easily be duplicated by competitors (Porter 2001). 
Second, non-VRIN IT resources can be combined with other non-VRIN organisational resources to produce IT-enabled resources. An example, of an IT-enabled resource is a geographically dispersed team of people supported by a videoconferencing tool (Nevo and Wade 2010).

Third, VRIN IS capabilities are developed from interactions that occur between non-VRIN IT resources and other non-VRIN organisational resources. For example, a geographically dispersed team's communication capability is developed through opportunities to apply a videoconferencing tool in making team-based decisions (Nevo and Wade 2010). The accumulated culture, history, learning and experience from the team's interaction with the tool cannot be duplicated, thus giving the communication capability its VRIN properties (Teece and Pisano 1994).

\subsection{Business Analytics Capabilities and Frameworks}

Taken as a whole, the preceding findings demonstrate that IS capabilities are more likely to yield competitive advantage than IT resources. Furthermore, the extant IS literature provides extensive support for the link between IS capabilities and organisational value and competitive advantage (Bhatt, Grover and Grover 2005; Johnston and Carrico 1998; Saraf, Langdon and Gosain 2007). This is particularly important since BA capabilities are also IS capabilities.

There are a number of BA and business intelligence (BI) capability maturity frameworks, from both the academic and practitioners literature (see for example Davenport and Harris 2001; Watson et al. 2001; Eckerson 2009; Yeoh and Koronios 2010 and Raber et al. 2012). None of this work is theoretically grounded in the resource-based view and refined and validated empirically. This gap in knowledge will be addressed through the development of a BACF. Capability frameworks are important instruments for information management (Rozemeijer 2007) and BA is an important application field for these frameworks.

From the extant literature, we identified two important BA capability frameworks, both in the form of maturity models (Davenport and Harris 2007; Raber et al. 2012). The earliest of these was the 5 stages of analytical competition model proposed by Davenport and Harris (2007). In this model, BA capabilities are structured hierarchically. For example, Davenport and Harris (2007) envisaged the overall BA capability of an organisation to be comprised of three lowerlevel BA capabilities: human, technological and organisational. This two-level hierarchical structure is also consistent with other conceptualisations of IS capabilities (e.g. Barreto 2010; Pavlou and El Sawy 2006).

Davenport and Harris's (2007) model was derived from extensive industry experience and case studies of world leading analytics organisations. For this reason, the model has a high degree of practical relevance but lacks a theoretical foundation. In contrast, the BA capability maturity model proposed by Raber et al. (2012) does have a theoretical foundation. For example, Raber et al. (2012) draw on IS success models and their underlying theoretical foundations as the basis for their model. The model consists of $58 \mathrm{BA}$ capabilities grouped into five distinct areas that represent IS concepts including: (i) strategy, (ii) social system, (iii) technical system, (iv) quality and (v) use/impact. Like Davenport and Harris's (2007) model, Raber et al.'s (2012) model also has practical relevance. This is because BA practitioners, specialists and executives played a key role in the development and evaluation of the model.

A limitation of the aforementioned models is neither incorporates dynamic capabilities. Becker et al. (2010) argue that in an era of rapidly changing business environments the resource-based view, particularly dynamic capabilities, should be used as the theoretical foundation for BA maturity models. In view of this, this study aims to develop a holistic, theoretically-grounded and practically relevant BACF that is based on the resource-based view and includes dynamic capabilities. 


\section{RESEARCH APPROACH}

In this section, we discuss the research approach and methodologies used to produce the BACF.

\subsection{Thematic Content Analysis}

The capabilities that constituted the initial version of the BACF were obtained from a thematic content analysis of the extant BA literature. First, the term BA capability was qualified. This was done by extrapolating resource-based view capability conceptualisations to the BA context. For example, as previously mentioned, in the resource-based view a capability is conceptualised as the ability to utilise resources in order to perform a certain task, and is produced from the interaction between IT assets and other organisational resources. In line with this, a BA capability was defined as: 'the ability to utilise resources to perform a BA task, based on the interaction between IT assets and other firm resources'.

Next, a sample of 51 publications focused on BA was sourced from the extant literature. This sample included major IS journals/conferences (e.g. Senior Scholars' Basket of 8, European Conference on IS (ECIS) and International Conference on IS (ICIS)), as well as the most highly cited publications between 1991 and 2014 from all other outlets.

The 51 publications were then analysed thoroughly in order to identify any keywords, themes or phrases that corresponded to the previously mentioned definition of a BA capability. All such items were assigned a specific definition that was in turn used to identify other instances of that capability. Three cycles of analysis and interpretation of the publications produced the $16 B A$ capabilities (brief BA capability definitions are provided in Appendix 1). The BA capabilities were grouped into four capability areas based on similarities. These are:

- $\quad$ Governance

A Mechanism for managing the use of BA resources and the assignment of decisionrights and accountabilities to align BA initiatives with organisational objectives (Weill and Ross 2004).

- $\quad$ Culture

Tacit and explicit organisational norms, values and behavioural patterns that form over time and lead to systematic ways of gathering, analysing and disseminating data (Leidner and Kayworth 2006).

- People

Individuals who use BA as part of their job function (Davenport et al. 2007).

- Technology

Development and use of hardware, software and data within BA activities (Negash 2004).

Figure 1 shows the initial BACF with the 16 BA capabilities grouped within the four BA capability areas that comprise the overall BA capability. Higher quality BA capabilities will lead to improved value and competitive advantage. 


\section{BA Capabilities $\quad \underline{\text { Capability Areas }}$}

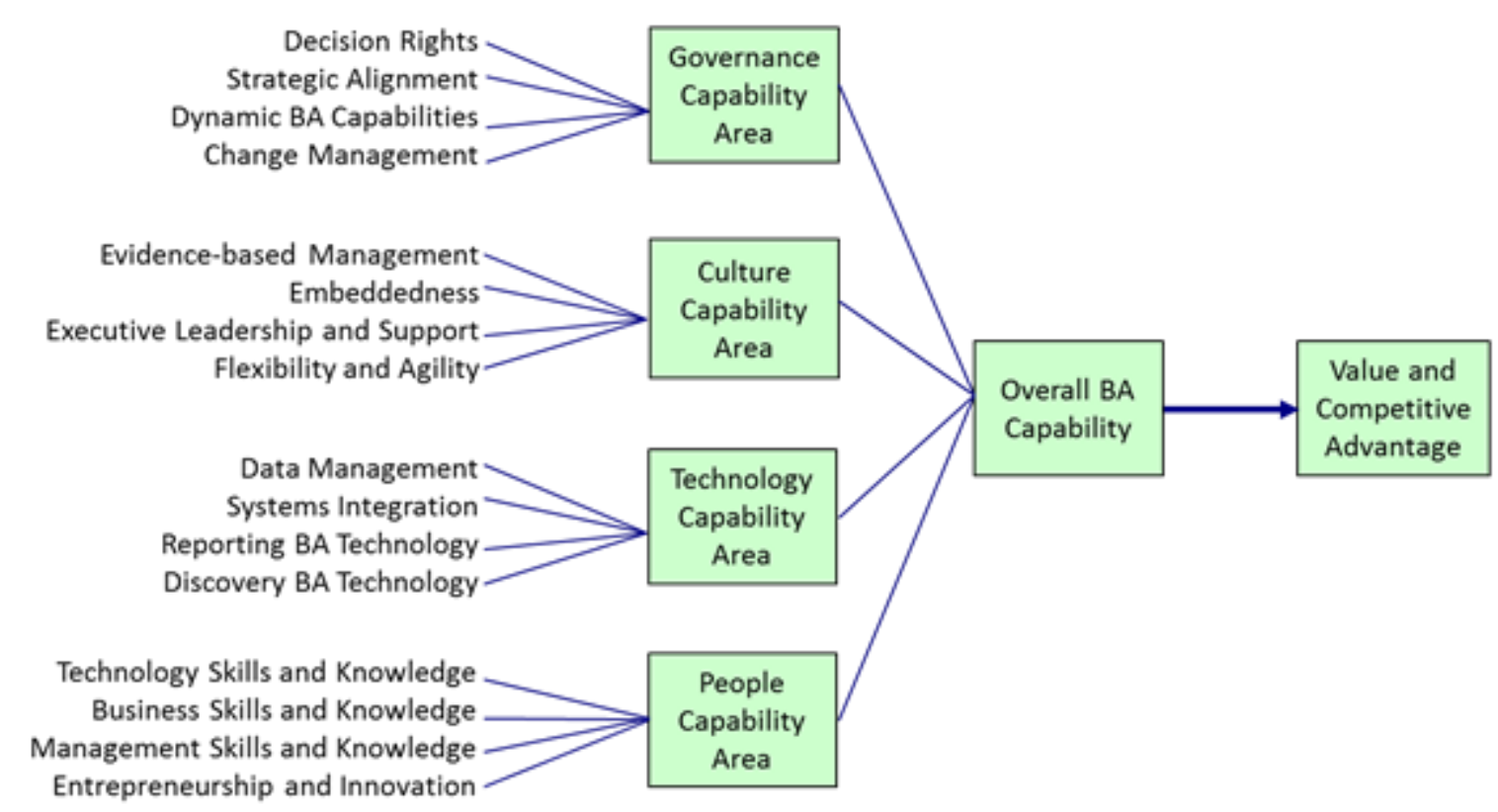

Figure 1: Initial Business Analytics Capability Framework.

\section{DELPHI STUDY}

In IS research, there are two fundamental research quality criteria that need to be taken into account: (i) theoretical and methodological rigor and (ii) practical relevance (Moody 2000).

A Delphi study was used to further develop and refine the BACF. The use of a Delphi study further enhances the methodological rigor of the BACF. However, importantly, it also serves to enhance the overall practical relevance and utility of the BACF through direct input from experienced BA experts.

A Delphi study is a qualitative research methodology, which involves iterative cycles of questionnaire preparation, collation and analysis of responses, concept refinement and the provision of feedback to participants, ideally culminating in a consensus of opinion (Skulmoski et al. 2007). Satisfaction measures are used to determine whether a consensus has been reached (Worrell et al. 2013).

A Delphi study is used for two main reasons. First, it is well suited to the development of conceptual frameworks such as the BACF (Okoli and Pawlowski 2004). Second, it offers several important advantages over a focus group including; participant anonymity, no need for faceto-face meetings, it is relatively free from the influence of social pressure and dominant personalities, participants can be sourced from a wider geographical area and they can respond at their convenience (Stewart and Shamdasani 1990).

Three key design considerations in a Delphi study are: the number of participants; selection of participants; and the number of rounds (Okoli and Pawlowski 2004). We aimed to have 15 participants as this provides a broad range of opinions and having more should not make a significant difference to the results (Dalkey 1969). However, 20 participants will be invited in order to allow for the possibility of attrition. Participants included leading Australian academic and practitioner BA experts to strengthen the generalisability of the outcomes. Each participant required a minimum of 5 years experience in BA.

Studies have shown that three rounds are usually sufficient to achieve an expert consensus. Studies have also shown that after three rounds participant interest declines and response fatigue sets in (Skulmoski et al. 2007). In view of this, in this study, the decision whether to conduct a subsequent round will be based on whether a consensus has been reached, or if the 
number of participants falls below a certain level. Similar to Indulska et al. (2009), consensus is correlated with a minimum satisfaction/importance measure of 8.0 and a maximum standard deviation of 2.0. In line with Dalkey (1969), the minimum number of participants required for a round is 15 .

\section{DELPHI STUDY DISCUSSION}

This section first discusses details of the Delphi study participants, response rates for each round and the data analysis approach used. Then, for each round, changes to the BACF are discussed.

\subsection{Participants, response rates and data analysis}

In all, 20 participants including 8 from academia and 12 from industry were invited to participate. The academics included 4 professors, 2 lecturers, a senior lecturer and a research fellow. The practitioners included 10 managers, a senior consultant and technical specialist from a range of industries including banking, finance, telecommunications, retail and software. Sixteen of the participants were from Melbourne, 3 were from Sydney and 1 was from Switzerland. Participants had on average 14 years of BA experience.

The response rate in the first round was $80 \%$ (4 academics and 12 practitioners). The response rates for the remaining rounds were $75 \%$ ( 4 academics and 11 practitioners) for the second round and 80\% (4 academics and 12 practitioners) for the third round. Importantly, the response rates all exceed $70 \%$, which is the recommended minimum requirement for rigor (Mullen 2003).

The Delphi study produced a mixture of qualitative and quantitative data. The qualitative data was used to refine the BA capability definitions and identify key concepts and themes. The quantitative data was summarised using simple descriptive statistics and used to assess the level of consensus among the participants with respect to the BA capability definitions, and to rank the BA capabilities in descending order of importance within each capability area within the BACF.

\subsection{Outcomes of Round 1}

In the first round, participants were provided with a table containing very brief definitions of the capabilities. Participants were asked to add up to three more key aspects, which had been overlooked in the existing definitions. In addition to this, participants were also asked to suggest up to four more capabilities that they thought should be added to the table. Two types of change are discussed below: changes to the capabilities and changes to the capability descriptions. The criteria for accepting recommended changes were agreement between two or more participants or a change that was judged to yield a new or important insight by the researchers.

\subsubsection{Changes to the capabilities}

The capability 'Decision Rights' was renamed to 'Decision Rights and Responsibilities' for two reasons. First, rights were considered different from responsibilities and should therefore be combined in the definition. Second, responsibilities were considered an important facet of this capability. The capability 'Change Management' was renamed to 'Impact and Change Management' to reflect better the scope of the capability. A capability labelled 'Flexibility and Agility' was removed from the framework as $25 \%$ of participants agreed that it overlapped with the 'Impact and Change Management' capability. Several additional capabilities were suggested, however only one, 'Communication', was supported by more than one participant. It was added to the framework.

Several suggestions for changes involved capabilities that were synonyms for existing capabilities. For example, 'the ability to champion BA' is already in the framework as 'Executive Leadership and Support'. Nearly $70 \%$ of the participants did not suggest any additional 
capabilities. This suggests that the BA capabilities identified in this study were robust and holistic.

\subsubsection{Changes to the definitions of capabilities}

A total of 62 changes were made to capability definitions, of which 38 were changes recommended by more than one participant and 24 were changes deemed to yield a new and important insight. 30 of the changes were suggested by practitioner participants, 9 by academic participants and the remainder by both practitioner and academic participants. This suggests strong participation by both types of participant.

Two examples of the many changes concern the definitions of 'Impact and Change Management' and 'Data Management'. For 'Impact and Change Management', participants added user involvement, rewards and the value of BA. For 'Data Management', participants added data quality, single version of the truth (practitioners only), master data and meta-data.

\subsubsection{Areas of disagreement}

Two capabilities where considerable disagreement occurred were 'Dynamic BA Capabilities' and 'Management Skills and Knowledge'. There were many suggestions for 'Dynamic BA Capabilities' but none were in agreement or considered to yield a new or important insight. This may be due to the more abstract nature of dynamic capabilities, which is essentially a firstorder concept, intended to renew existing BA capabilities (Pavlov and El Sawy 2006). Several participants considered project management to be an important facet of 'Management Skills and Knowledge', while an equal number considered project management to be a general or normal capability not directly related to BA. It was retained in the definition as it is considered important by Davenport and Harris (2007).

\subsection{Outcomes of Round 2}

In the second round, participants were provided with a table containing detailed definitions of the capabilities. Participants were asked to provide comments about each capability definition, to rate the importance of each capability on a scale from 1 (not important) to 10 (very important), and to rate their satisfaction with each capability on a scale from 1 (not satisfied) to 10 (very satisfied). See Table 1 on page 10 for satisfaction and importance ratings for this round.

\subsubsection{Changes due to Comments}

In the second round, there were no direct disagreements between the participants or further changes to the names of the capabilities; however a large number of minor changes were made to all of the capability definitions. In summary, 11 participants suggested an average of 5 changes each, while the remaining 4 participants did not suggest any changes. Of the changes made, 9 were suggested by more than 1 participant and 43 were considered to yield a new or important insight by the researchers. Specific details of the most significant changes are outlined as follows.

Interestingly, 5 participants made comments that suggested broader capability areas, including 'technology' and 'culture', with details that closely match the capability area definitions provided in section 4 of this paper. For example, when discussing C11 (Visualisation BA Technology), one participant suggested that "a general technology capability is needed". Also, when discussing C16 (Entrepreneurship and Innovation), another participant noted they were "key aspects of their ability to innovate is organisational culture". These, and other similar changes, clarify the BA capabilities that constitute the technology and cultural aspects of an organisational BA initiative and enhance the work of Davenport and Harris (2007).

Only two out of the 53 changes in this round were deletions and both were for the same capability, C3 (Dynamic BA Capabilities). The term 'renewal' was removed from the description as 2 participants were 'not sure what it meant' and noted that it 'did not resonate with their logic'. Also, the sentence about intellectual property retainment was deleted as 
participants found it placed too much importance on the retention of intellectual property within dynamic capabilities.

Many minor additions were made to the capability definitions. A noteworthy change was for C14 (Business Skills and Knowledge) where it was noted that people in BA-related management roles "perform an intermediary role: translating and communicating the potential value of BA (insights) to the senior executive team". This is important because much of the literature related to this capability discusses the importance of executive managers understanding the value of BA (Pfeffer and Sutton 2006; Shanks et al. 2012). However, much less is said about the ways in which this can be achieved. C14 (Business Skills and Knowledge) was further refined in order to make it less ambiguous and more parsimonious, following comments from participants that the definition was "too long" and "too broad".

C9 (Data Management) and C16 (Entrepreneurship and Innovation) were extended in order to make certain points clearer and less ambiguous. The phrase "single version of the truth" was replaced with "common usage and understanding of the data" in $\mathrm{C} 9$ and the phrase was replaced with "think outside the square" was replaced with "ability to rationally assess risks and benefits".

Finally, the definitions of $\mathrm{C}_{13}$ (Technology Skills and Knowledge) and C14 (Business Skills and Knowledge) were modified to make it clearer that they refer to the combined skills and knowledge found 'throughout the organisation' rather than the skills and knowledge of a particular individual. These changes were based on comments from participants, for example "finding people with all of the above skills at a deep level would be extremely rare (I don't know anyone like this)"

\subsubsection{Importance Ratings}

Average importance ratings for 13 of the 16 BA capabilities were above the required threshold of 8.0 with maximum standard deviation of 2.0, indicating a high level of consensus after the second round of the Delphi study. The three BA capabilities that did not meet the threshold were C6 (Embeddedness) (7.8: 2.0), C10 (Systems Integration) (7.6: 2.1) and C12 (Discovery BA Technology) (8.1: 2.2).

\subsubsection{Satisfaction Ratings}

The participant's satisfaction ratings were averaged, and only 6 of the capabilities were above the threshold of 8.0 with maximum standard deviation of 2.0. 5 other capabilities were very close to the threshold and the remaining 5 capabilities were well below the threshold. The high variation was mainly due to 1 participant who assigned ratings of 1 out of 10 for several capabilities.

\subsection{Outcomes of Round 3}

In the third round, as in the second, participants were provided with a table containing detailed definitions of the capabilities. Participants were asked to provide comments about each capability definition, to rate the importance of each capability on a scale from 1 (not important) to 10 (very important), and to rate their satisfaction with each capability on a scale from 1 (not satisfied) to 10 (very satisfied). See Table 1 on page 10 for satisfaction and importance ratings for this round.

\subsubsection{Changes due to Comments}

In the third round, there were no direct disagreements between the participants or further changes to the names of the capabilities. In summary, 9 participants suggested a total of 34 changes, of which 14 were deemed important enough to modify the capability definitions. Minor changes were made to the definitions for 7 capabilities (C1, C2, C6, C9, C12, C15 and C16). Of these changes, only one was suggested by more than 1 participant. For example, in relation to $\mathrm{C} 1$ (Decision Rights and Responsibilities) two participants shared the view that "people responsible for decisions must be held accountable". Another example of a minor change was to C12 (Discovery BA Technology). One participant suggested that "text mining as 
one of the analysis tools" be included in the description, as C12 involved the analysis of unstructured data.

\subsubsection{Importance Ratings}

There was strong consensus among the participants with respect to the average importance ratings for the capabilities. Please note $\mathrm{C}_{1}$ (Decision Rights and Responsibilities) and $\mathrm{C}_{3}$ (Dynamic BA Capabilities) had the same rating and standard deviation and therefore were listed in alphabetical order. C10 (Systems Integration) and C12 (Discovery BA Technology) also had the same rating but $\mathrm{C} 10$ had a lower standard deviation (1.5) than $\mathrm{C} 12$ (1.6) and therefore was ranked higher. The minimum average importance rating in this round was 8.0 (C10 (Systems Integration)) as required and the maximum standard deviation was 1.6 (C10 (Systems Integration) and C12 (Dynamic BA Capabilities), which was well below the required 2.0. Most of the importance ratings and all of the standard deviations decreased between rounds 2 and 3 .

\subsubsection{Satisfaction Ratings}

A strong consensus was achieved among the participants with respect to the average satisfaction ratings for the capabilities. For example, the minimum average satisfaction rating was 8.1 for C6 (Embeddedness), which was above the required 8.0 and the maximum standard deviation was 1.5 for C6 and C13 (Technology Knowledge and Skills), which was well below the required 2.0. All of the average satisfaction ratings increased and the standard deviations decreased between rounds 2 and 3. The ratings for 6 capabilities $\left(\mathrm{C}_{1}, \mathrm{C}_{2}, \mathrm{C}_{3}, \mathrm{C}_{4}, \mathrm{C}_{5}, \mathrm{C}_{16} 6\right)$ increased by more than a point and the standard deviations for 8 capabilities $\left(\mathrm{C}_{1}, \mathrm{C}_{3}, \mathrm{C}_{4}, \mathrm{C}_{5}\right.$, $\mathrm{C} 11, \mathrm{C} 12, \mathrm{C} 14, \mathrm{C} 16)$ decreased by more than a point. This shows that changes to the definitions from round 2 led to a significant increase in participant satisfaction.

\begin{tabular}{|c|c|c|c|c|c|c|c|c|}
\hline \multirow[t]{2}{*}{ BA Capabilities } & \multicolumn{2}{|c|}{$\begin{array}{l}\text { Round 2 } \\
\text { Average } \\
\text { Satisfaction } \\
\text { Measures }\end{array}$} & \multicolumn{2}{|c|}{$\begin{array}{l}\text { Round 3 } \\
\text { Average } \\
\text { Satisfaction } \\
\text { Measures }\end{array}$} & \multicolumn{2}{|c|}{$\begin{array}{c}\text { Round 2 } \\
\text { Average Importance } \\
\text { Measures }\end{array}$} & \multicolumn{2}{|c|}{$\begin{array}{c}\text { Round } 3 \\
\text { Average Importance } \\
\text { Measures }\end{array}$} \\
\hline & Rating & $\begin{array}{l}\text { Standard } \\
\text { Deviation }\end{array}$ & Rating & $\begin{array}{l}\text { Standard } \\
\text { Deviation }\end{array}$ & Rating & \begin{tabular}{|l} 
Standard \\
Deviation
\end{tabular} & Rating & $\begin{array}{l}\text { Standard } \\
\text { Deviation }\end{array}$ \\
\hline $\begin{array}{l}\text { Decision Rights } \\
\text { and } \\
\text { Responsibilities } \\
\text { (C1) }\end{array}$ & 8.2 & 1.6 & 9.1 & 0.6 & 8.5 & 1.4 & 8.7 & 1.0 \\
\hline $\begin{array}{c}\text { Strategic } \\
\text { Alignment } \\
\text { (C2) }\end{array}$ & 7.8 & 1.9 & 9.0 & 0.9 & 9.2 & 1.1 & 9.4 & 0.7 \\
\hline $\begin{array}{l}\text { Dynamic BA } \\
\text { Capabilities } \\
\text { (C3) }\end{array}$ & 7.8 & 2.2 & 8.8 & 1.1 & 8.3 & 1.1 & 8.7 & 1.0 \\
\hline $\begin{array}{l}\text { Impact and } \\
\text { Change } \\
\text { Management } \\
\text { (C4) }\end{array}$ & 7.9 & 1.9 & 8.9 & 0.8 & 8.4 & 1.7 & 8.9 & 0.9 \\
\hline $\begin{array}{l}\text { Evideno-based } \\
\text { Management } \\
\text { (C5) }\end{array}$ & 7.8 & 2.6 & 9.1 & 0.9 & 8.7 & 1.0 & 8.5 & 0.9 \\
\hline $\begin{array}{l}\text { Embeddedness } \\
\text { (C6) }\end{array}$ & 8.0 & 1.8 & 8.1 & 1.5 & 7.8 & 2.0 & 8.0 & 1.1 \\
\hline $\begin{array}{l}\text { Executive } \\
\text { Leadership and } \\
\text { Support } \\
\text { (C7) }\end{array}$ & 8.3 & 1.6 & 8.9 & 1.0 & 8.9 & 2.0 & 9.1 & 1.1 \\
\hline $\begin{array}{l}\text { Communication } \\
\text { (C8) }\end{array}$ & 8.5 & 1.4 & 9.0 & 0.8 & 8.4 & 1.9 & 9.1 & 1.1 \\
\hline $\begin{array}{c}\text { Data } \\
\text { Management } \\
\text { (C9) }\end{array}$ & 8.0 & 1.9 & 8.9 & 1.1 & 8.8 & 1.3 & 9.3 & 0.7 \\
\hline $\begin{array}{c}\text { Systems } \\
\text { Integration } \\
\text { (C10) }\end{array}$ & 7.7 & 2.1 & 8.3 & 1.4 & 7.6 & 2.1 & 8.1 & 1.6 \\
\hline $\begin{array}{l}\text { Reporting and } \\
\text { Visualisation BA } \\
\text { Technology } \\
\text { (C11) }\end{array}$ & 7.9 & 2.5 & 8.7 & 1.2 & 8.3 & 1.8 & 8.9 & 0.9 \\
\hline $\begin{array}{l}\text { Discovery BA } \\
\text { Technology } \\
\text { (C12) }\end{array}$ & 7.7 & 2.4 & 8.3 & 1.1 & 8.1 & 2.2 & 8.1 & 1.5 \\
\hline $\begin{array}{l}\text { Technology } \\
\text { Skills and } \\
\text { Knowledge } \\
\text { (C13) }\end{array}$ & 7.6 & 2.4 & 8.4 & 1.5 & 8.3 & 1.3 & 8.6 & 0.8 \\
\hline $\begin{array}{l}\text { Business Skills } \\
\text { and Knowledge } \\
\text { (C14) }\end{array}$ & 8.3 & 2.5 & 8.8 & 0.8 & 8.9 & 1.1 & 9.1 & 0.9 \\
\hline $\begin{array}{l}\text { Management } \\
\text { Skills and } \\
\text { Knowledge } \\
\text { (C15) }\end{array}$ & 8.2 & 1.5 & 8.9 & 0.8 & 8.8 & 1.3 & 8.7 & 1.1 \\
\hline $\begin{array}{l}\text { Entrepreneurship } \\
\text { and Innovation } \\
\text { (C16) }\end{array}$ & 8.3 & 2.5 & 9.0 & 0.9 & 8.7 & 1.2 & 9.2 & 0.9 \\
\hline
\end{tabular}

Table 1: BA Capability Satisfaction and Importance Measures 
The shaded areas in Table 1 show the measures that did not meet the criteria for consensus e.g. minimum rating of 8.0 and maximum standard deviation of 2.0

\section{SUMMARY DELPHI STUDY KEY FINDINGS}

There were four key findings from the Delphi study which are reflected in the revised BACF (Figure 2). First, participants initially had diverse expectations of what constitutes an organisational BA capability. This was not surprising given the absence of an explicit definition for the term BA capability within the extant literature. For example, both Davenport and Harris (2007) and Raber et al. (2012) produced BA capability maturity models but did not qualify, nor explicitly define what is meant by the term BA capability.

\section{BA Capabilities $\quad \underline{\text { Capability Areas }}$}

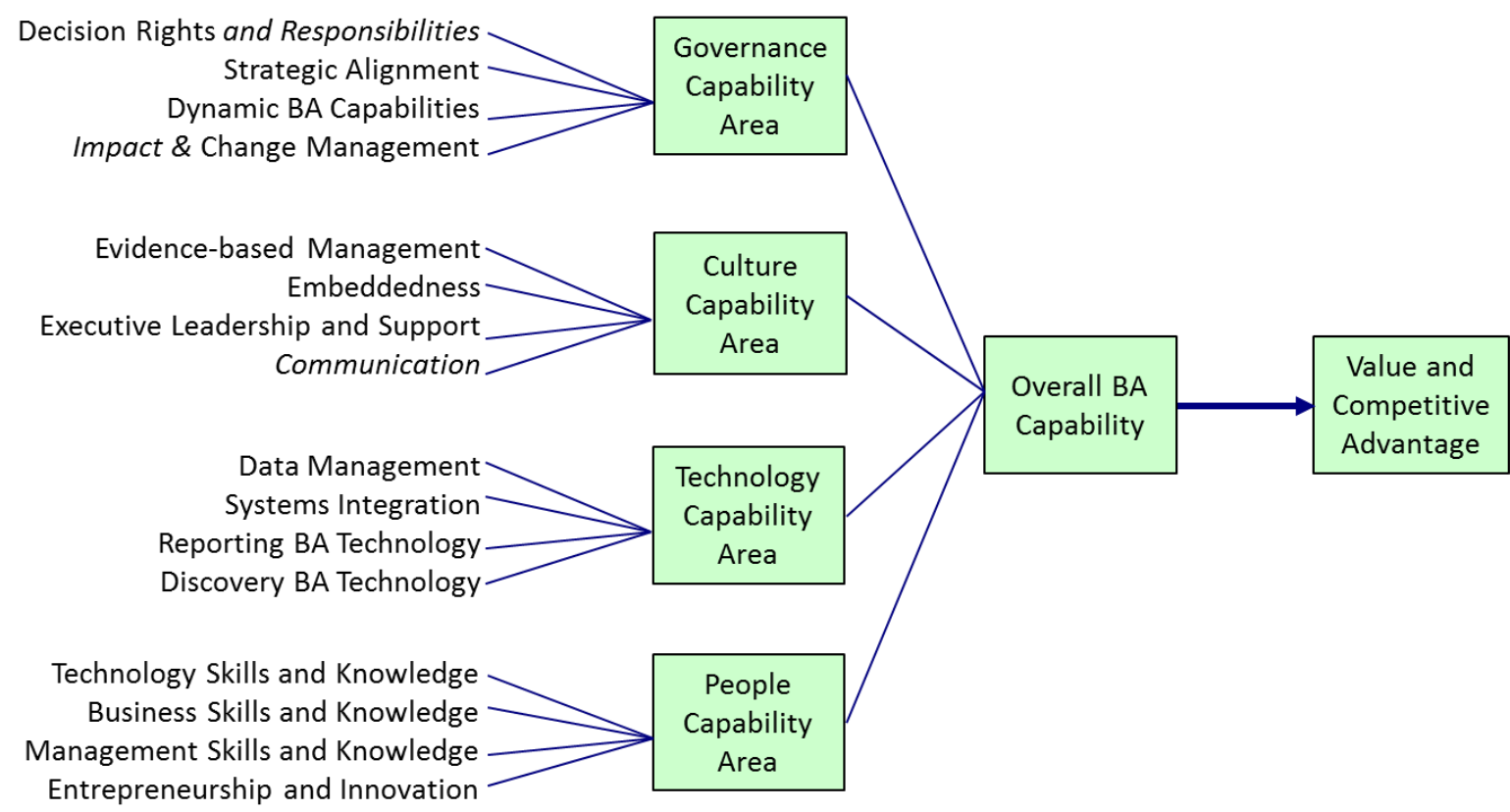

Figure 2: Revised BACF based on Delphi Study.

Second, a consensus amongst participants was achieved after three rounds, which is expected in a Delphi study (Skulmoski et al. 2007). The response rates for each of the three rounds were above the recommended minimum of $70 \%$ required for rigor. However, the response rates between the two groups of experts differed widely. For example, only half of the academics participated in each round. By contrast, all practitioners participated in the first and third rounds and only one missed the second round. These high practitioner response rates served to enhance the overall practical relevance of the results and the BACF itself.

Third, there were minor changes to the overall structure (e.g. replacement of 'Flexibility and Agility' with 'Communication' capability) and significant changes to all of the capability definitions. The inclusion of 'Communication' capability was critical as it was rated the most important capability within the 'culture' capability area (See Table 1), and is consistent with Davenport and Harris (2007) and Laursen and Thorlund (2010), who strongly emphasise the importance of communication in BA initiatives.

Finally, this study found direct support for the 'technology' and 'culture' capability areas. Together with 'governance' and 'people' these capability areas are common themes in the IS literature (De Bruin 2009). However, the unique contribution to knowledge in this study is a rigorous and relevant set of clearly defined BA capabilities.

Full definitions and literature sources for the BA capabilities in the revised BACF are shown in Appendix 2. 


\section{CONCLUSION}

In this paper, we have described the development of a BACF that is comprised of $16 \mathrm{BA}$ capabilities that are evenly distributed across four main capability areas. The initial conceptual framework was developed based on the resource-based view theory of the firm and a rigorous thematic content analysis of the BA literature. This framework was revised and confirmed in a Delphi study. The Delphi study saw significant changes made to capability descriptions in the framework, minor but important changes to the overall structure, and a high level of consensus achieved after three rounds.

The contributions of this paper are relevant to both researchers and practitioners. For researchers, the BACF will provide a rigorous and relevant set of clearly defined BA capabilities. For practitioners, it will provide a systematic means of understanding the range of BA capabilities that are required for BA initiatives. The importance rankings will help in prioritising the development of BA capabilities, and the detailed descriptions will help in the planning and development of comprehensive BA capabilities. Furthermore, a framework for identifying given capabilities in BA is valuable for companies as it provides benefits by enabling improvements in business processes, firm performance and creating competitive advantages.

In future work, these capabilities will be operationalised to measure their as-is status, thus enabling organisations to identify key areas of strength and weakness and better prioritise future capability improvement efforts. Developing measures for each BA capability enables the BACF to form the basis for a BA capability maturity model. Future work should examine how the BA capabilities develop over time and their relationship to organisational strategy, performance, value and competitive advantage.

\section{REFERENCES}

Anderson-Lehman, R., Watson, H.J., Wixom, B.H., and Hoffer, J.A. 2004. Continental Airlines Flies High with Real-Time Business Intelligence, MISQ Executive, 3(4), 163-176.

Allmendinger, G. and Lombreglia, R. 2005. Four Strategies for the Age of Smart Services. Harvard Business Review, 83(10), 131-145.

Aral, S. and Weill, P. 2007. IT Assets, Organisational Capabilities and Firm Performance: How Resource Allocations and Organisational Differences Explain Performance Variation, Organisation Science, 18(5), 1-18.

Barney, J. 1991. "Firm resources and sustained competitive advantage," Journal of Management(17:1), pp 99-120.

Barney, J.B. 2001. Is the Resource-Based "View" a Useful Perspective for Strategic Management Research? Yes, Academy of Management Review, 26(1), 41-56.

Barreto, I. 2010. Dynamic Capabilities: A Review of Past Research and an Agenda for the Future, Journal of Management, 36(1), 256-280.

Becker, Joerg; Niehaves, Bjoern; Poeppelbuss, Jens; and Simons, Alexander, 2010. "Maturity Models in IS Research" ECIS 2010 Proceedings. Paper 42.

Bhatt, G. D., Grover, V., \& Grover, V. 2005. Types of information technology capabilities and their role in competitive advantage: an empirical study. Journal of Management Information Systems, 22(2), 253-277.

Cosic, R; Shanks, G; Maynard, S (2012) "Towards a business analytics capability maturity model". ACIS 2012 : Location, location, location : Proceedings of the 23 rd Australasian Conference on Information Systems 2012, Australasian Conference on Information Systems (23rd : 2012 : Geelong, Victoria), pp 1-11.

ComputerWeekly.com 2013. Global Business Intelligence Spending To Double in Four Years. $\begin{array}{llll}\text { accessed } & \text { 12th } & \text { August } & \text { 2014, from }\end{array}$ 
http://www.computerweekly.com/news/2240175647/Global-business-intelligencespending-to-double-in-four-years

Dalkey, N.C. 1969. An experimental study of group opinion, Futures, 1(5), 408-426.

Davenport, T.H. and Harris, J.G. 2007. Competing on Analytics: The New Science of Winning . Harvard Business School Press, Boston.

de Bruin, T. 2009. Business process management : theory on progression and maturity. $\mathrm{PhD}$ thesis, Queensland University of Technology.

Eckerson, W. 2009 TDWI's Business Intelligence Maturity Model, Chatsworth.

Gartner. 2015. Flipping to Digital Leadership: Insights from the 2015 CIO Agenda Report, Gartner Group.

Helfat, C.E., Finkelstein, S., Mitchell, W., Peteraf, M.A., Singh, H., Teece, D.J., and Winter, S.G. 2007. Dynamic Capabilities: Understanding Strategic Change in Organisations. Blackwell, Carlton.

Indulska, M., Recker, J., Rosemann, M., \& Green, P. 2009. Business process modeling: Current issues and future challenges. In Advanced Information Systems Engineering, 501-514. Springer Berlin/Heidelberg.

Johnston, H. R., \& Carrico, S. R. 1988. Developing capabilities to use information strategically. MIS Quarterly, 37-48.

Kohavi, R., Rothleder, N. and Simoudis, E. 2002. Emerging Trends in Business Analytics, Communications of the ACM, 45(8), 45-48.

Lahmann, G., 2010. Business Intelligence Maturity Models: An Overview. In D’Atri, Ferrara and Spagnoletti (eds.) Proceedings of the VII Conference of the Italian Chapter of AIS, Naples, Italy.

Laursen, G.H.N., and Thorlund, J. 2010. Business analytics for managers: Take business intelligence beyond reporting. John Wiley and Sons, Hoboken, NJ.

Leidner, D. E., and Kayworth, T. 2006. A review of culture in information systems research: Toward a theory of information technology cultural conflict, MIS Quarterly, 30:2, 357399.

Moody, Daniel L. 2000, "Building links between IS research and professional practice: improving the relevance and impact of IS research." Proceedings of the twenty first international conference on Information systems. Association for Information Systems.

Mullen, P. M. 2003. Delphi: myths and reality. Journal of Health Organization and Management, 17(1), 37-52.

Negash, S. 2004. Business Intelligence," Communications of the Association for Information Systems, 13, 177-195.

Nevo, S. and Wade, M. 2010. The Formation and Value of IT-Enabled Resources: Antecedents and. Consequences of Synergistic Relationships, MIS Quarterly, 34(1), 163-183.

Okoli, C. and Pawlowski, S.D. 2004. The Delphi method as a research tool: an example, design considerations and applications, Information \& Management, 42, 15-29.

Pavlou, P.A. and El Sawy. O.A. 2006. From IT competence to competitive advantage in turbulent environments: The case of new product development, Information Systems Research 17(3), 198-227.

Pfeffer, J. and Sutton, R. 2006. Evidence-based management. Harvard Business Review, 84(1), 62-68. 
Piccoli, G. and Watson, R. 2008. Profit from Customer Data by Identifying Strategic Opportunities and Adopting the "Born Digital" Approach, MIS Quarterly Executive, 7(3), 113-122.

Raber, D., Winter, R. and Wortmann, F. 2012. Using Quantitative Analyses to Construct a Capability Maturity Model for Business Intelligence. In Proceedings of the 45th Hawaii International Conference on System Science (HICSS), 4219-4228.

Rozemeijer, E. 2007. Frameworks for IT Management. Van Haren Publishing.

Saraf, N., Langdon, C. S., \& Gosain, S. 2007. IS application capabilities and relational value in interfirm partnerships. Information Systems Research, 18(3), 320-339.

Shanks, G., Bekmamedova, N., Frederic, A., and Daly, M. 2012. "Embedding Business Intelligence Systems within Organisations," in A. Respicio, F. Adam and G. PhillipsWren (eds) Fusing Decision Support Systems into the Fabric of the Context, Amsterdam, NL: IOS Press,113-124.

Sharma, R., Reynolds, P., Scheepers, R., Seddon, P., and Shanks, G. 2010. Business Analytics and Competitive Advantage: A Review and Research Agenda. In A. Respicio, F. Adam and G. Phillips-Wren (eds.) Bridging the socio-technical gap in DSS - Challenges for the next decade. IOS Press, Amsterdam.

Sharma, R. and Shanks, G. 2011. The Role of Dynamic Capabilities in Creating Business Value from IS Assets, AMCIS 2011 Proceedings - All Submissions, Paper 135.

Skulmoski, G. J., Hartman, F.T. and Krahn, J. 2007. The Delphi Method for Graduate Research. Journal of Information Technology Education, 6, 1-21.

Stewart, D.W. and Shamdasani, P.N. 1990. Focus groups: Theory and practice. Sage, Newbury Park, CA.

Teece D.J. and Pisano G. 1994. The dynamic capabilities of enterprises: an introduction. Industrial and Corporate Change, 3(3), 537-556.

Wade, M. and Hulland, J. 2004. Review: The Resource-Based View and Information Systems Research: Review, Extension, and Suggestions for Future Research, MIS Quarterly, 28(1), 107-142.

Watson, H., T. Ariyachandra and R. Matyska 2001 Data Warehousing Stages of Growth, Information Systems Management, 18(3), 42-50.

Watson, H.J. and Wixom, B.H. 2007. The current state of business intelligence. Computer, 40(9), 96-99.

Watson, H.J. 2010. BI-based Organizations. Business Intelligence Journal, 15(2), 4.

Watson, H.J. 2011. Business Analytics Insight: Hype or Here to Stay?, Business Intelligence Journal, 16(1), 4-8.

Weill, P. and Ross, J.W. 2004. IT Governance: How Top Performers Manage IT Decision Rights for Superior Results. Harvard Business School Publishing, Boston, MA.

Wernerfelt, B. 1984. A Resource-Based View of the Firm, Strategic Management Journal, 5(2), 171-180.

Williams, S., and Williams, N. 2007. The Profit Impact of Business Intelligence. Morgan Kaufmann Publishers, San Francisco, CA

Worrell, J., Gangi, P. and Bush, A. 2013. Exploring the use of the Delphi method in accounting information systems research, International Journal of Accounting Information Systems, 14(3), 193-208

Yeoh, W. and A. Koronios 2010. Critical Success Factors for Business Intelligence Systems, Journal of Computer Information Systems, 50(3), 23-32 


\section{Appendix 1}

\begin{tabular}{|c|c|}
\hline BA Capability & Definition \\
\hline Decision-Rights & $\begin{array}{l}\text { Determining those responsible for making each kind of decision to ensure the } \\
\text { right person makes the right decision at the right time (Weill and Ross 2004). }\end{array}$ \\
\hline $\begin{array}{l}\text { Strategic } \\
\text { Alignment }\end{array}$ & $\begin{array}{l}\text { Aligning BA initiatives with organisational goals (Williams and Williams } \\
\text { 2007). }\end{array}$ \\
\hline $\begin{array}{l}\text { Dynamic BA } \\
\text { Capabilities }\end{array}$ & $\begin{array}{l}\text { Continuous renewal of organisation's BA resource-base and capabilities to } \\
\text { respond to changes in dynamic business environments (Shanks et al. 2011). }\end{array}$ \\
\hline $\begin{array}{l}\text { Change } \\
\text { Management }\end{array}$ & $\begin{array}{l}\text { To manage resistance from, and provide training to, people impacted by BA } \\
\text { initiatives (Anderson-Lehman et al. 2004). }\end{array}$ \\
\hline $\begin{array}{l}\text { Evidence-based } \\
\text { Management }\end{array}$ & $\begin{array}{l}\text { Culture where authority, reputation, intuition and ad-hoc decision-making are } \\
\text { superseded by decisions based on data and quantitative analysis (Pfeffer and } \\
\text { Sutton 2006). }\end{array}$ \\
\hline Embeddedness & $\begin{array}{l}\text { Extent to which BA has permeated the organisation's social fabric and become } \\
\text { ingrained into people's values and daily work habits (Shanks et al. 2012). }\end{array}$ \\
\hline $\begin{array}{l}\text { Executive } \\
\text { Leadership and } \\
\text { Support }\end{array}$ & $\begin{array}{l}\text { Ability of senior managers to infuse a passion for BA and data-driven } \\
\text { decision-making throughout the organisation (Laursen and Thorlund 2010). }\end{array}$ \\
\hline $\begin{array}{l}\text { Flexibility and } \\
\text { Agility }\end{array}$ & $\begin{array}{l}\text { Receptivity of non-managerial BA personnel to changes in business } \\
\text { environment (Cheese 2005). }\end{array}$ \\
\hline Data Management & $\begin{array}{l}\text { Mechanism for ensuring data used in BA initiatives is fit for purpose and } \\
\text { meets the information requirements of the organisation (Watson and Wixom } \\
\text { 2007) }\end{array}$ \\
\hline $\begin{array}{l}\text { Systems } \\
\text { Integration }\end{array}$ & $\begin{array}{l}\text { Seamless integration of BA and operational systems to exploit the capabilities } \\
\text { of both (Myerson 2002). }\end{array}$ \\
\hline $\begin{array}{l}\text { Reporting and } \\
\text { Visualisation BA } \\
\text { Technology }\end{array}$ & $\begin{array}{l}\text { Development and utilisation of reports, dashboards, scorecards, OLAP and } \\
\text { data visualisation technologies to display output information in a format } \\
\text { readily understood by its users e.g. managers and other key decision-makers } \\
\text { (Ramaamurthy et al. 2008). }\end{array}$ \\
\hline $\begin{array}{l}\text { Discovery BA } \\
\text { Technology }\end{array}$ & $\begin{array}{l}\text { Development and utilisation of sophisticated statistical and data mining } \\
\text { software to explore data and identify useful correlations, patterns and trends } \\
\text { and extrapolate them to forecast what is likely to occur in the future (Negash } \\
\text { 2004). }\end{array}$ \\
\hline $\begin{array}{l}\text { Technology Skills } \\
\text { and Knowledge }\end{array}$ & $\begin{array}{l}\text { Skills and knowledge of BA technology specialists including data } \\
\text { management, application development and IT in general (Davenport and } \\
\text { Harris 2007). }\end{array}$ \\
\hline $\begin{array}{l}\text { Business Skills and } \\
\text { Knowledge }\end{array}$ & $\begin{array}{l}\text { Skills and knowledge of BA business specialists e.g. accounting and finance } \\
\text { (Davenport and Harris 2007). }\end{array}$ \\
\hline $\begin{array}{l}\text { Management Skills } \\
\text { and Knowledge }\end{array}$ & $\begin{array}{l}\text { Skills and knowledge of management specialists responsible for enterprise- } \\
\text { wide BA initiatives or projects in local business units (Davenport et al. 2010). }\end{array}$ \\
\hline $\begin{array}{l}\text { Entrepreneurship } \\
\text { and Innovation }\end{array}$ & $\begin{array}{l}\text { Skills and knowledge of managers to use BA technologies to develop } \\
\text { innovative and more effective processes and products that lead to better } \\
\text { organisational performance and SCA (Sharma et al. 2010). }\end{array}$ \\
\hline
\end{tabular}




\section{Appendix 2}

\begin{tabular}{|c|c|}
\hline BA Capability & Definition \\
\hline $\begin{array}{l}\text { Decision Rights } \\
\text { and } \\
\text { Responsibilities } \\
\text { (C1) }\end{array}$ & $\begin{array}{l}\text { Assignment of decision rights and responsibilities by determining; (i) } \\
\text { those responsible for making certain decisions in relation to the } \\
\text { planning, implementation and applications of BA, (ii) where } \\
\text { appropriate, those who will provide the input for such decisions, and } \\
\text { (iii) those who will be held accountable for the resulting actions and } \\
\text { outcomes of these decisions. It is important that a person responsible } \\
\text { for making a certain decision is held accountable for the resulting } \\
\text { actions and outcomes (Weill and Ross 2004). }\end{array}$ \\
\hline $\begin{array}{l}\text { Strategic } \\
\text { Alignment } \\
(\mathrm{C} 2)\end{array}$ & $\begin{array}{l}\text { Alignment of an organisation's BA initiatives with its business strategy. } \\
\text { It is a two-way relationship in the sense that BA initiatives can help } \\
\text { measure and enforce a business strategy, whilst business strategy } \\
\text { necessarily shapes BA initiatives as they evolve. This requires a clearly } \\
\text { defined business strategy that is enunciated to all staff and translated } \\
\text { into a set of measurable outcomes. It also requires a genuine } \\
\text { commitment to the strategy demonstrated by the decisions and actions } \\
\text { of senior people (Williams and Williams 2007). }\end{array}$ \\
\hline $\begin{array}{l}\text { Dynamic BA } \\
\text { Capabilities } \\
\left(\mathrm{C}_{3}\right)\end{array}$ & $\begin{array}{l}\text { Ability to reconfigure and leverage an organisation's BA resources and } \\
\text { capabilities in order to respond to changes in the business } \\
\text { environment in a timely and efficient manner. Such responsiveness } \\
\text { requires the ability to identify potential BA opportunities (Search), } \\
\text { prioritise those opportunities based on business need, risk and } \\
\text { technology maturity (Select) and then funding and implementing the } \\
\text { opportunities (Asset Orchestration) resulting in new and unique } \\
\text { resource configurations (Sharma and Shanks 2011). }\end{array}$ \\
\hline $\begin{array}{l}\text { Impact and } \\
\text { Change } \\
\text { Management } \\
\text { (C4) }\end{array}$ & $\begin{array}{l}\text { Ability to manage human, technological and process impacts across } \\
\text { the organisation arising from BA initiatives. This involves managing } \\
\text { changes to the systems environment and the provision of training and } \\
\text { rewards in order to; (i) demonstrate the value and utility of BA, (ii) } \\
\text { encourage the adoption of new BA technologies and work practices, } \\
\text { (iii) mitigate potential resistance, and (iv) manage expectations. } \\
\text { Furthermore, it is important that all types of BA users, from managers } \\
\text { to operational staff, are involved in the initial planning of a BA } \\
\text { initiative (Negash 2004). }\end{array}$ \\
\hline $\begin{array}{l}\text { Evidence-based } \\
\text { Management } \\
\left(\mathrm{C}_{5}\right)\end{array}$ & $\begin{array}{l}\text { A culture where (i) formal authority, reputation, intuition and ad-hoc } \\
\text { decision-making are preceded by decisions based on data, (ii) BA } \\
\text { users, including power users, are encouraged to actively participate in } \\
\text { the development of a data-driven environment, (iii) there is trust in } \\
\text { data and the BA tools used to analyse data, (iv) whenever possible, } \\
\text { assertions are substantiated with data, and (v) although the emphasis } \\
\text { is on fact-based decision making, there is still some room for intuition } \\
\text { and ad-hoc decision-making, particularly when the required data is not } \\
\text { available (Pfeffer and Sutton 2006). }\end{array}$ \\
\hline
\end{tabular}




\begin{tabular}{|c|c|}
\hline $\begin{array}{l}\text { Embeddedness } \\
\text { (C6) }\end{array}$ & $\begin{array}{l}\text { Extent to which BA has permeated the fabric of an organisation e.g. } \\
\text { business processes and values (e.g. appreciation for BA analysis tools } \\
\text { and data-driven insights). It is reflected in the extent to which people } \\
\text { routinely use data and BA tools to solve problems and make decisions. } \\
\text { It is facilitated by sharing metadata and the use of a collaboration } \\
\text { portal. The portal enables work to be shared and intellectual property } \\
\text { to be spread throughout the organisation. Where appropriate, models } \\
\text { are used to make decisions on an ongoing and pervasive basis (Shanks } \\
\text { et al. 2012). }\end{array}$ \\
\hline $\begin{array}{l}\text { Executive } \\
\text { Leadership and } \\
\text { Support } \\
\text { (C7) }\end{array}$ & $\begin{array}{l}\text { Ability of senior managers and executives to advocate the use of BA } \\
\text { systems and data-driven decision-making throughout the organisation. } \\
\text { This requires (i) a clear vision, (ii) first-hand experience and } \\
\text { understanding of the benefits and successes of BA and (iii) the } \\
\text { promotion of this vision and understanding throughout the } \\
\text { organisation, and (iv) the provision of financial and material support } \\
\text { for BA initiatives (Laursen and Thorlund 2010). }\end{array}$ \\
\hline $\begin{array}{l}\text { Communication } \\
\text { (C8) }\end{array}$ & $\begin{array}{l}\text { BA personnel across the organisation foster a culture of open } \\
\text { communication and trust between themselves and other business } \\
\text { users. This involves listening carefully to the needs of business users } \\
\text { and translating BA concepts into every-day business language. It is } \\
\text { facilitated by close and frequent contact via a variety of different } \\
\text { communication channels (Davenport and Harris 2007). }\end{array}$ \\
\hline $\begin{array}{l}\text { Data } \\
\text { Management } \\
\text { (C9) }\end{array}$ & $\begin{array}{l}\text { Mechanism for (i) sourcing data for BA initiatives from multiple } \\
\text { channels, including operational/transactional systems and third-party } \\
\text { sources, (ii) ensuring its quality e.g. consistency, accessibility, } \\
\text { flexibility, integrity, timeliness and availability and (iii) integrating it } \\
\text { with existing data in a central repository e.g. enterprise data } \\
\text { warehouse. It also includes master data management and metadata } \\
\text { management to ensure data definitions are consistent across } \\
\text { organisational units to encourage common usage and understanding of } \\
\text { the data (Watson and Wixom 2007). }\end{array}$ \\
\hline $\begin{array}{l}\text { Systems } \\
\text { Integration } \\
(\mathrm{C} 10)\end{array}$ & $\begin{array}{l}\text { Seamless integration of BA systems with operational/transactional } \\
\text { systems at the process, technology and data levels in order to exploit } \\
\text { the capabilities of both. Systems integration is important for leveraging } \\
\text { value from BA and is facilitated by the flexible design of technology } \\
\text { infrastructure and systems architecture. It also introduces a degree of } \\
\text { complexity and therefore should be done with care and careful } \\
\text { consideration of the need (Sharma and Shanks 2011). }\end{array}$ \\
\hline $\begin{array}{l}\text { Reporting and } \\
\text { Visualisation BA } \\
\text { Technology } \\
\text { (C11) }\end{array}$ & $\begin{array}{l}\text { Ability to develop and utilise self-service analysis applications e.g. } \\
\text { reports, dashboards, scorecards, online analytical processing (OLAP) } \\
\text { and data visualisation technologies, which display output in a user- } \\
\text { friendly format that is readily understood by non-technical users. } \\
\text { These applications are particularly useful for addressing structured } \\
\text { problems and facilitate the visual manipulation and exploration of data } \\
\text { (Watson and Wixom 2007). }\end{array}$ \\
\hline
\end{tabular}




\begin{tabular}{|c|c|}
\hline $\begin{array}{l}\text { Discovery BA } \\
\text { Technology } \\
(\mathrm{C} 12)\end{array}$ & $\begin{array}{l}\text { Ability to develop and utilise quantitative and qualitative analysis tools } \\
\text { (e.g. statistical analysis, data mining, text mining and predictive } \\
\text { analysis) to facilitate the semi-automated analysis of numerical, semi- } \\
\text { structured and unstructured data to; (i) discover new actionable } \\
\text { insights from patterns in the data, and (ii) extrapolate patterns found } \\
\text { in the data to predict what is likely to occur in the future. These tools } \\
\text { are particularly useful for addressing less structured problems (Negash } \\
\text { 2004). }\end{array}$ \\
\hline $\begin{array}{l}\text { Technology Skills } \\
\text { and Knowledge } \\
\text { (C13) }\end{array}$ & $\begin{array}{l}\text { Combined skills and knowledge of BA technology specialists across the } \\
\text { organisation including; programming, optimisation software, } \\
\text { algorithms, database/file management, ETL (Extraction, } \\
\text { Transformation and Loading), data warehousing, software } \\
\text { development methodologies and high level architectures. Some level of } \\
\text { business domain and industry knowledge is necessary to apply these } \\
\text { skill sets. Furthermore, teams should consist of specialists whose skills } \\
\text { are complementary to other team members (Davenport and Harris } \\
\text { 2007). }\end{array}$ \\
\hline $\begin{array}{l}\text { Business Skills } \\
\text { and Knowledge } \\
\text { (C14) }\end{array}$ & $\begin{array}{l}\text { Combined skills and knowledge of people throughout the organisation } \\
\text { that are involved in the business side of BA initiatives including; (i) } \\
\text { fundamental business principles, and (ii) depth of domain knowledge } \\
\text { of the organisation's key products, services, processes, value chain and } \\
\text { industry in general. It also includes the ability to; (i) network, (ii) seek } \\
\text { out opportunities and threats, and (iii) develop and drive an agenda. } \\
\text { Some level of technical expertise is necessary to understand the data } \\
\text { available to them and communicate with BA technical specialists } \\
\text { (Anderson-Lehman et al. 2004). }\end{array}$ \\
\hline $\begin{array}{l}\text { Management } \\
\text { Skills and } \\
\text { Knowledge } \\
\text { (C15) }\end{array}$ & $\begin{array}{l}\text { Combined skills and knowledge of people in BA related management } \\
\text { roles throughout the organisation to (i) prioritise and manage BA } \\
\text { projects, (ii) redesign business processes as a result of implementing } \\
\text { BA, and (iii) translate, communicate and sell the potential values and } \\
\text { benefits of BA to senior executives (e.g. senior executives and general } \\
\text { managers). Some level of technical expertise is necessary to } \\
\text { understand the data available to them and communicate with BA } \\
\text { technical specialists (Davenport and Harris 2007). }\end{array}$ \\
\hline $\begin{array}{l}\text { Entrepreneurship } \\
\text { and Innovation } \\
\text { (C16) }\end{array}$ & $\begin{array}{l}\text { Combined skills and knowledge of BA managers and other BA users } \\
\text { throughout the organisation to (i) continually challenge the status quo, } \\
\text { (ii) manage new innovation as a separate activity to continuous } \\
\text { improvement, (iii) create and promote a technical innovation team, as } \\
\text { well as (iv) an innovation forum made up of innovation teams from } \\
\text { other business units. It is characterised by an entrepreneurial mindset } \\
\text { and vision and the ability to rationally assess risks and benefits. It is } \\
\text { enhanced through the provision of some authoritative autonomy and } \\
\text { financial independence, which provides BA managers with a degree of } \\
\text { freedom to pursue value-creating actions. (Sharma et al. 2010). }\end{array}$ \\
\hline
\end{tabular}

Copyright: (C) 2015 Cosic, Shanks \& Maynard. This is an open-access article distributed under the terms of the Creative Commons Attribution-NonCommercial 3.0 Australia License, 
which permits non-commercial use, distribution, and reproduction in any medium, provided the original author and AJIS are credited.

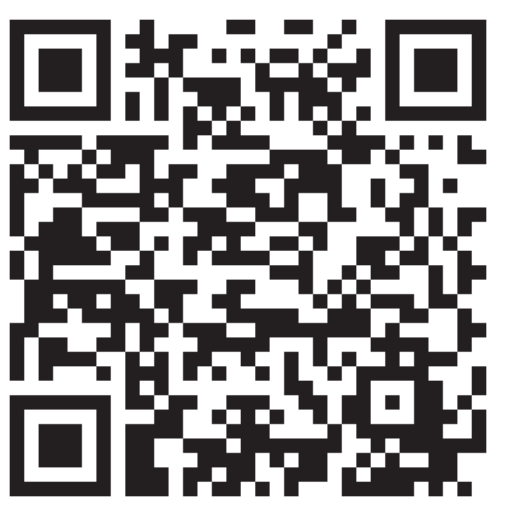

